\title{
TURKERIZAÇÃO E GESTÃO ALGORÍTMICA DO TRABALHO EM PLATAFORMAS DE MICROTAREFAS
}

\author{
Matheus Viana Braz ${ }^{1}$ orcid.org/0000-0003-1193-9753 \\ Carolina Dal-col Vianna ${ }^{2}$ orcid.org/0000-0002-7231-7117 \\ Vitória Carvalho Bertolaccini ${ }^{2}$ orcid.org/0000-0002-5846-740X \\ Paula Santiago Ramos ${ }^{2}$ orcid.org/0000-0002-1084-0658 \\ Ana Clara Santos Silva ${ }^{2}$ orcid.org/0000-0001-5130-7668
}

RESUMO. No Brasil, quando tratamos da plataformização do trabalho, é ainda incipiente a literatura sobre o fenômeno que denominamos turkerização do trabalho, relacionado à terceirização de microtarefas em plataformas específicas, como Appen e Amazon Mechanical Turk, por exemplo. Por meio de um estudo teórico-reflexivo, objetivamos demarcar algumas particularidades do trabalho turkerizado, de maneira a contribuir com a exploração da heterogeneidade e polissemia que assume a noção de trabalho digital na atualidade. Ao passo que representa a radicalização da flexibilização do trabalho, compreendemos a turkerização como o arquétipo de formas de trabalho que parecem se proliferar em nossa sociedade, marcadas notadamente por algumas características centrais: 1) o trabalho tende a ser cada vez mais encarado como serviço; 2) exacerba-se a competição a ponto de trabalhadores de diversas geografias do mundo concorrerem entre si, em tempo real, na busca por rendimentos financeiros; 3) os processos de trabalho são cada vez mais condicionados pela gestão algorítmica, o que limita as vias de comunicação entre os trabalhadores, coloca obstáculos à mobilização coletiva e produz efeitos paradoxais no âmbito das dinâmicas de prazer, sofrimento e reconhecimento no trabalho.

Palavras-chave: Plataformização; Gestão Algorítmica; Microtrabalho; Economia de bico; Turkerização.

\footnotetext{
1 Professor de Psicologia do Trabalho e das Organizações na Universidade do Estado de Minas Gerais (UEMG), unidade de Divinópolis - MG. Doutorado pelo Programa de Pós-graduação em Psicologia da Universidade Estadual Paulista (UNESP/FCLA). Correspondente no Brasil do Réseau International de Sociologie Clinique (RISC). Coordenador do Laboratório de Trabalho, Saúde e Processos de Subjetivação (LATRAPS-UEMG).

${ }^{2}$ Graduanda do curso de Psicologia na Universidade do Estado de Minas Gerais (UEMG), unidade de Divinópolis - MG.
} 


\title{
TURKERIZATION AND ALGORITHMIC MANAGEMENT IN MICROTASK PLATFORMS
}

\begin{abstract}
In Brazil, when we talk about crowdwork, the literature on the phenomenon that we call turkerization is still incipient, related to the microtasks crowdsourcing, such as Appen and Amazon Mechanical Turk, for example. Through a theoretical-reflective study, we aim to highlight some differences between uberization and turkerization, in order to contribute to the exploration of heterogeneity and polysemy of the digital work concept. While it represents the radicalization of work flexibilization, we understand turkerization as the archetype of work forms that seem to proliferate in our society, arranged by some central characteristics: 1) work tends to be increasingly conceived as a service; 2 ) competition is exacerbated to the point that workers from different geographies of the world compete with each other, in real time, in the search for financial income; 3) work processes are increasingly conditioned by algorithmic management, which limits the means of communication between workers, put obstacles to collective mobilization and produces paradoxical effects in the context of the pleasure dynamics, suffering and recognition at work.
\end{abstract}

Keywords: Platformization; Algorithmic management; Microwork, Gig economy; Turkerization. 


\section{Introdução}

No século XVIII, precisamente em 1770, o inventor húngaro Wolfgang von Kempelen tornou pública a principal criação de sua vida, chamada The Turk. Tratava-se da primeira máquina de xadrez dotada de inteligência artificial capaz de "pensar" e "derrotar" grandes enxadristas da época. Após cerca de cinquenta anos de sua criação, contudo, descobriu-se que $O$ Turco era, na realidade, uma ilusão mecânica, por meio da qual um jogador de xadrez escondido movia as peças no interior da máquina. Foi baseada nesta invenção que Jeff Bezzos escolheu o nome Amazon Mechanical Turk (AMT) para designar uma plataforma lançada em 2005 e controlada pela Amazon Web Services, no qual trabalhadores terceirizados são pagos para realizarem microtarefas voltadas ao aprendizado e treinamento de máquinas, processamento e coleta de dados, bem como à realização de pesquisas de mercado. Se Bezzos a descreveu como uma espécie de inteligência artificial artificial é porque a plataforma concentra serviços escaláveis, sob demanda, que não podem ser feitos por máquinas, mas que paradoxalmente sustentam toda a cadeia de produção da inteligência artificial difundida pelo mercado (Berg et al., 2018, Casilli, 2019). Não à toa, a própria empresa se remete aos microtrabalhadores da AMT como turkers (Amazon Mechanical Turk, 2020).

Atualmente, a AMT é a maior plataforma do mundo voltada ao mercado de microtarefas, contabilizando mais de 500 mil trabalhadores em sua base de registros (Amazon Mechanical Turk, 2020). Segundo modelo analítico construído pelo Banco Mundial (Kuek et al., 2015), estima-se que exista aproximadamente 5,8 milhões de microtrabalhadores no mundo e, destes, $33 \%$ possuem ensino superior completo e cerca de $70 \%$ são pessoas de até 35 anos, que possuem outra ocupação principal. Em média, esses profissionais dedicam 20 horas semanais ao mercado de microtasks (Berg et al., 2018).

No Brasil, quando tratamos da plataformização do trabalho, é ainda incipiente a literatura (Kalil, 2019; Moreschi, Pereira \& Cozman, 2020) sobre o fenômeno que denominamos turkerização do trabalho, isto é, todo microtrabalho que serve à preparação e à produção de inteligência artificial. Embora se imbrique no que se designa taskificação do trabalho (Grohmann, 2020), neste artigo objetivamos demarcar algumas particularidades do trabalho turkerizado, de maneira a contribuir com a exploração da heterogeneidade e 

polissemia que assume a noção de trabalho digital na gig economy (Van Doorn, 2017; Casilli, 2019).

Por meio de um estudo teórico-reflexivo, baseado na Sociologia Clínica, sustentamos a premissa de que turkerização se consolida como um fenômeno que traduz, em status nascendi, a radicalização da flexibilização do trabalho, assentada em uma ideologia gerencialista (Gaulejac, 2007) na qual os custos marginais de serviço das organizações amiúde tendem a zero. Com efeito, compreendemos a turkerização como o arquétipo de formas de trabalho que parecem se proliferar em nossa sociedade, marcadas notadamente por algumas características centrais: 1) o trabalho tende a ser cada vez mais encarado como serviço; 2) exacerba-se a competição a ponto de trabalhadores de diversas geografias do mundo concorrerem entre si, em tempo real, na busca por rendimentos financeiros; 3) os processos de trabalho são cada vez mais condicionados pela gestão algorítmica, o que limita as vias de comunicação entre os trabalhadores, coloca obstáculos à mobilização coletiva e produz efeitos paradoxais no âmbito das dinâmicas de prazer, sofrimento e reconhecimento no trabalho.

\section{Plataformização do trabalho}

Com o advento do regime de acumulação flexível do capital, oriundo do paradigma toyotista de produção, desde os anos de 1970 o mundo do trabalho passou por transformações substanciais (Antunes, 2018). A globalização financeira, consolidada por intermédio da universalização das redes de informação e eletrônicas, não somente favoreceu este movimento como foi protagonista de uma revolução gerencialista (Gaulejac, 2007; 2011), operada inicialmente no seio de organizações transnacionais, porém que na atualidade tem sua ideologia difundida em grande parte do mercado de trabalho (Gaulejac, 2007, Viana Braz, 2019). Remetemo-nos, portanto, a um fenômeno que impulsionou o redesenho da divisão internacional do trabalho, alterou os padrões de competição globais e fez da flexibilidade a principal ordenadora dos modos de sociabilidade do trabalho contemporâneo (Antunes, 2018).

A ideologia gerencialista carrega em seu bojo uma concepção utilitarista, objetivista, funcionalista e pragmática do indivíduo, visto de forma restrita como um consumidor e um capital a ser frutificado no trabalho, mediante a mensuração de atividades humanas em indicadores de desempenho (Gaulejac, 2007). Com efeito, acompanhamos na atualidade o declínio da sociedade salarial (Castel, 2003), representada pelo aumento da informalidade, da precarização do trabalho e da atomização das formas de emprego (terceirização, quarteirização, pejotização, trabalho intermitente etc) (Antunes, 2018, Viana Braz, 2021). 
$\mathrm{Na}$ esteira da tese da "destruição criativa" do economista austríaco Joseph A. Shumpeter (1911/1982), nos anos de 1980 economistas liberais (Caldas, 2000) defendiam que a Revolução Digital traria consigo a redução dos custos de produção, o estímulo ao aumento da demanda dos consumidores e de novos mercados, assim como daria cada vez mais oportunidades para as pessoas trabalharem, mediante salários mais altos, em funções ainda inexistentes, mormente nos setores de tecnologia. De fato, as primeiras premissas se consolidaram. O desenvolvimento da informatização possibilitou diminuição de custos e aumento da demanda agregada, mediante o crescimento escalável de rendimento e liquidez das organizações. A multiplicação das oportunidades e dos altos salários, entretanto, não se efetivou, pois atualmente a evolução das tecnologias torna possível a criação de modelos de negócios escaláveis e repetíveis, cujo aumento de receita não é acompanhado de expansão proporcional de custos com infraestrutura e pessoal ${ }^{3}$. Esse é o caso das startups, isto é, organizações que se utilizam de inovações tecnológicas para escalar suas receitas, rentabilidade e multiplicar seus valores de mercado, sem que haja aumento proporcional de custos.

Neste cenário, o aumento dos ciclos de disrupções tecnológicas se corrobora com a tendência à escassez de empregos com salários médios (vinculados a atividades rotineiras e repetitivas) e de aumento de empregos com altos salários, que exigem alta qualificação e teor criativo (Rodrik, 2011, Kalil, 2019). Para garantir a redução de seus custos marginais, trabalhos que antes eram feitos de forma regular, mediante proteção social e trabalhista, são terceirizados e relegados à informalidade pelas organizações. Não faltam, aqui, eufemismos para designar estes trabalhadores: consultores independentes, empreendedores de si, trabalhadores independentes, contribuidores etc.

A título de ilustração, segundo o Instituto Brasileiro de Geografia e Estatística (IBGE, 2020), no terceiro trimestre de 2020 a taxa de desemprego no Brasil chegou a 11,8\%, o que corresponde a 12,8 milhões de brasileiros desempregados, sem contar ainda os 5,7 milhões de desalentados e 29,1\% de taxa de subutilização. Além disso, quase quatro em cada 10 brasileiros estavam na informalidade em suas ocupações $\left(36,9 \%\right.$ dos brasileiros ocupados $\left.{ }^{4}\right)$ e $26 \%$ da população ocupada trabalhava por conta própria (IBGE, 2020). Ademais, o estudo de Manzano \& Krein (2020) corrobora os dados citados, ao constatar que os condutores de automóveis, táxis e caminhonetes, assim como os condutores de motocicletas estão na quarta e sétima

\footnotetext{
${ }^{3}$ É em função desta premissa que Jeremy Rifkin (2014) defende que a economia do compartilhamento tende a permitir que empresas logrem, com cada vez mais frequência, um custo marginal de serviços que tende a zero. ${ }^{4}$ No período referido, o Brasil possuía 83.347 milhões de pessoas ocupadas (IBGE, 2020).
} 
posição dos trabalhos que mais cresceram, no Brasil, respectivamente, desde o ano de 2016 (período concomitante a expansão dos aplicativos de transporte e entregas). Os autores apontam, todavia, que a remuneração desses trabalhadores está abaixo do valor médio que recebiam há oito anos (Manzano \& Krein, 2020).

Para discutirmos a realidade destes trabalhadores que vivem nas franjas da informalidade, faz-se necessário compreender o desenvolvimento da plataformização do trabalho. Em especial, remetemo-nos à trabalhos que são geridos, mediados e controlados por plataformas digitais (Casilli, 2019) e que se dividem em três categorias (Woodcock \& Graham, 2019; Grohmann, 2020): 1) plataformas de trabalho freelance, como Helpie, Singu, Stootie, WeDoLogos, 99 Designs e GetNinjas; 2) plataformas de mobilidade, as quais dependem de localização determinada, como Uber, 99pop, iFood, Deliveroo, EasyTaxi, Kapten e DiDi; 3) e plataformas de microtrabalho, onde microtarefas são terceirizadas por variadas empresas para o aperfeiçoamento e treinamento de dados para inteligência artificial, como Amazon Mechanical Turk, Appen, LionBridge e MicroWorkers.

Segundo Grohmann \& Qiu (2020), a plataformização produz uma reconfiguração do trabalho, por meio da taskificação das atividades, na qual se prescinde de vínculos empregatícios, proteção social, trabalhista e jornadas de trabalho delimitadas. Ao passo que o trabalho passa a ser encarado como um serviço, os custos de produção, operacionais e os riscos são também transferidos para os trabalhadores (Antunes, 2018). Ainda que estas plataformas se coloquem como mediadoras de diferentes agentes econômicos, se estabelece uma falsa relação comercial, caracterizada pela parassubordinação e hipossuficiência do trabalhador (Manzano \& Krein, 2020; Abílio, 2019; 2020). Tratamos de forma mais ampla do fenômeno da uberização, em que a centralização do controle e a dispersão do trabalho são regidas pela financeirização, marcadas pela concentração de renda e operacionalizadas mediante novos modos de gerenciamentos autotaylorizados (Abílio, 2019; 2020).

Embora se trate de um fenômeno em expansão no mundo todo, Grohmann \& Qiu (2020) destacam três características elementares que interferem na gramática do trabalho plataformizado no Sul Global. Primeiro, em países emergentes e subdesenvolvidos a economia informal não é novidade. Parte significativa da classe trabalhadora no Brasil historicamente garante seu sustento no mercado informal, não regulamentado, vivendo da economia dos bicos, de modo que sobretudo em regiões periféricas a viração é mais a regra do que a exceção (Rizek, 2006; Antunes, 2018). Segundo, há que se considerar as distinções e particularidades entre os próprios países do Sul Global (Grohmann \& Qiu, 2020). Se de um lado Japão, Coréia do Sul e 
China gradualmente se posicionam como superpotências, em matéria de produção de inteligência artificial, as economias da América do Sul e África eventualmente se colocam em posições diametralmente opostas. Terceiro, não podemos desprezar as tradições revolucionárias do Sul Global, notadamente marcadas pela resistência anti-imperialista e póscolonial. Grohmann \& Qiu (2020), nessa esteira, defendem que a compreensão destes movimentos culturais trabalhistas assume papel relevante na consciência de classe, lutas e resistências dos trabalhadores de plataformas digitais.

Para avançarmos em nossas reflexões, faremos neste momento uma digressão, cuja finalidade é explicitar ao leitor a dinâmica de funcionamento das plataformas de microtarefas. Para tanto, retomamos o exemplo da Amazon Mechanical Turk, organização que instigou a proposição que denominamos turkerização. Embora a plataforma tenha se tornado pública em 2005, foi antes desenvolvida internamente para filtrar e corrigir informações de produtos duplicados em seus sistemas. Assim, foi criado um website e estes microserviços eram transferidos para outros trabalhadores da empresa, garantindo que os engenheiros e vendedores pudessem se dedicar a atividades de maior complexidade. Em troca, os trabalhadores ganhavam centavos de dólares por cada Human Intelligence Task (HIT) realizada (Casilli, 2019, Kalil, 2019).

Por se tratar de um negócio com alta margem, recorrência, baixa tributação, escalável, que não exigia estoques e possuía baixos custos de pessoal, em 2005 foi lançada oficialmente a AMT. Em termos práticos, empresas de diversas geografias do mundo terceirizam (em plataformas como a AMT), tarefas que servem para aperfeiçoar e treinar seus algoritmos de inteligência artificial. Estes serviços são fragmentados em microtarefas de baixa complexidade, contudo que não podem ser realizadas por máquinas. Tratam-se, portanto, de atividades de classificação e reconhecimento de imagens, categorizações de expressões faciais, análises de publicidades, moderação de conteúdo, experimentação de produtos, etc. Com efeito, tais atividades ficam disponíveis na plataforma e trabalhadores do mundo todo podem se registrar e se habilitar para realizá-las (contando que cumpram os requisitos exigidos pelo cliente). Para cada microtarefa aprovada pelo requisitante, o trabalhador recebe em sua conta online alguns centavos de dólares ou reais (Kalil, 2019).

Se Casilli (2019) defende que não há automatização tecnológica no mundo sem microtrabalho, é porque atualmente se constata que a inteligência artificial não somente é substancialmente dependente de supervisão como envolve, sobretudo para o treinamento de 
seus dados, um contingente expressivo de trabalhos que são terceirizados nestas plataformas ${ }^{5}$. Por isso, inclusive, que já em 2005 foram também lançadas a Universal Human Relevance System (UHRS) e a RaterHub, plataformas de microtrabalho controladas pela Microsoft e Google (Tubaro \& Casilli, 2019). Igualmente, estas plataformas se proliferaram de forma expressiva na última década, funcionam sete dias na semana, 24 horas por dia e contam com trabalhadores do mundo todo (Berg et al., 2018).

Ainda que pessoas de todo o mundo possam se registrar nas plataformas de microtarefas, trabalhadores de países subdesenvolvidos e em desenvolvimento recebem remunerações inferiores daqueles provenientes de países desenvolvidos. Segundo Berg et al. (2018), em 2017 os microtrabalhadores dos Estados Unidos ganhavam em média US\$7,50, enquanto os indianos recebiam US\$2,14 por hora. Ademais, a literatura (Berg et al., 2018; Casilli, 2019) sugere que a maior parte dos microtrabalhadores do mundo tem até 35 anos, vive em regiões metropolitanas e adentram neste mercado em busca de dinheiro. Conforme elucida Kalil (2019), as empresas têm seus ganhos aumentados em escala, pois a competição global por trabalhadores, online, em tempo real, lhes proporciona economia de tempo e redução de custos com pessoal. Por outro lado, os trabalhadores são atraídos pela flexibilidade e pela facilidade na realização de tarefas em variadas localidades.

Como as plataformas limitam a comunicação entre os próprios trabalhadores, não há um apoio institucional claro, as pessoas ficam à mercê da disponibilidade de trabalho e, quando algumas de suas tarefas são reprovadas, amiúde os requisitantes não apresentam justificativas claras e fundamentadas para tal. Os trabalhadores não têm autonomia para recorrer perante estas decisões. A flexibilidade, igualmente, por vezes os encerra em um círculo insidioso, pois ficam conectados o máximo possível a espera de boas oportunidades, independentemente do horário que possam surgir (Casilli, 2019). O trabalho turkerizado, portanto, é marcado por seu potencial de dispersão global, sem que as plataformas percam o controle dos trabalhadores. Embora difundam um discurso de trabalho autônomo de seus parceiros, tais organizações encerram os indivíduos em uma lógica de autogerenciamento subordinado (Abilio, 2020).

Ora, se partimos do pressuposto que o trabalho turkerizado se caracteriza como uma forma de uberização, qual a importância de se utilizar esta denominação? Neste momento, deparamo-nos com um ponto sensível deste texto. É preciso frisar que quando nos remetemos

\footnotetext{
${ }^{5}$ Embora não tenhamos um dado exato, em levantamento realizado no núcleo do Laboratório de Trabalho, Saúde e Processos de Subjetivação (LATRAPS - UEMG), mapeamos mais de cinquenta plataformas de microtarefas em operação no Brasil até o mês de novembro de 2020.
} 
a uberização é fundamental nos debruçarmos sobre os denominadores comuns de diferentes arranjos de trabalho. Contudo, suas particularidades também devem ser debatidas, pois são elas que nos permitem compreender os atravessamentos institucionais circunscritos nas vivências dos trabalhadores. Nesse sentido, defendemos que o trabalho turkerizado (microtrabalho direcionado à preparação de dados à inteligência artificial) se distingue das demais configurações laborais pelas seguintes características:

A turkerização tem maior potencial de expansão, interconexão e mobilidade, tal como o capital financeiro, o que torna os trabalhadores ainda mais descartáveis, pois passam a competir diretamente com trabalhadores de todo o mundo, em tempo real.

Em variados trabalhos plataformizados as organizações condicionam a disponibilidade de serviços em função da geolocalização do trabalhador. Todavia, no trabalho turkerizado essa perspectiva é ampliada e globalizada. Se o trabalhador pode realizar tarefas de requisitantes de diferentes localidades, a dinâmica de remuneração ocorre de forma arbitrária e assimétrica. Nas próprias plataformas, portanto, a hierarquização dos trabalhadores faz com que os residentes de países periféricos recebam atribuições que demandam menor qualificação e cujos rendimentos são inferiores àqueles pagos para trabalhadores de países desenvolvidos.

$>$ Os trabalhadores são ainda mais invisíveis e invisibilizados. Embora sejam essenciais ao mercado de tecnologia da informação e a toda sorte de informatização existente em nosso cotidiano, os trabalhadores não estão nas ruas, como os entregadores, mas trabalham silenciosamente em locais privados. O trabalho turkerizado parece ser praticamente desconhecido perante a população geral (Viana Braz, 2019). É também em razão desta faceta que Gray $\&$ Sury (2019) se remetem ao microtrabalho como o trabalho fantasma ${ }^{6}$ (ghost work).

Ao refletir sobre a plataformização do trabalho ou, de modo mais abrangente, sobre o fenômeno da uberização, é fundamental que consideremos estas particularidades, que representam novos modos de organização, controle e, inclusive, de processos de subjetivação no trabalho. No próximo tópico, acrescentaremos um ingrediente ainda não explorado (neste

\footnotetext{
${ }^{6}$ As dinâmicas de trabalho são tão impessoais que o trabalhador não conhece quem solicitou seu serviço e comumente nem sabe qual a finalidade da tarefa que lhe foi requisitada.
} 
texto) na equação do trabalho digital, porém que ocupa função determinante nas dinâmicas de prazer e sofrimento no trabalho: a gestão algorítmica.

\section{Gestão algorítmica do trabalho}

Algoritmos são unidades matemáticas criadas na computação para resolver problemas e, logo, a gestão algorítmica remete a dispositivos de prescrição, governança, supervisão e controle dos processos de trabalho (Abilio, 2019). Ora, se enfatizamos que a uberização do trabalho implica uma relação de autogerenciamento subordinado, é porque os trabalhadores têm seus dados extraídos e toda a gestão de seus trabalhos se opera mediante programação algorítmica (Abílio, 2019, Grohmann, 2020).

A gestão algorítmica se estrutura por intermédio de uma dinâmica específica de extração econômica, produtora de um triplo valor, conforme propõe Casilli (2019). O valor de qualificação implica o fato de que, para que estas plataformas funcionem, é preciso que seus algoritmos sejam constantemente qualificados e alimentados. Embora os microtrabalhadores ocupem uma função central neste quesito, destacamos que as organizações extraem o tempo todo informações de sua base de clientes e trabalhadores. Tais dados, por sua vez, são transformados de diferentes maneiras em valor monetário, que varia em função da finalidade da plataforma. Enfim, uma vez que estas plataformas operam com big data e deep learning, de forma a aperfeiçoar suas cadeias algorítmicas, o valor de automação corresponde ao potencial de criação de novas ferramentas e tecnologias. É nesta perspectiva que a Uber, por exemplo, coleta dados de seus usuários para fomentar o desenvolvimento de sua frota de veículos autônomos (Casilli, 2019).

Embora as plataformas sustentem um discurso de neutralidade algorítmica, esta modalidade de gestão do trabalho representa um controle político e ideológico que recai sobre os trabalhadores. No plano ideológico, Noble (2018) demonstra que as fórmulas algorítmicas, ainda que se pretendam objetivas e infalíveis, são feitas por pessoas, de classes sociais, gênero e raças específicas e, portanto, reproduzem dinâmicas específicas de poder, preconceitos, sexismo e toda uma sorte de perspectivas de indivíduos que ocupam posições privilegiadas em nossa sociedade. Se partirmos do pressuposto que parte significativa das plataformas são criadas ou ao menos diretamente influenciadas pela ideologia gerencialista hegemônica proveniente do Vale do Silício, as principais estratégias de gestão algorítmica do trabalho são desenhadas por elites tecnológicas representantes de uma tecnocracia digital que, sob a alcunha 
de um discurso meritocrático, pós-racial e pós-colonial, ocultam marcadores de gênero, território, classe e raça presentes não somente na cultura das empresas (mediante uma pluralidade de vieses de confirmação), como também em seus algoritmos (Noble \& Roberts, 2020).

No plano político, do controle sobre o trabalho, subsidiado pelas proposições de Mölhmann \& Zalmansson (2017), Grohmann (2020) destaca seis características da gestão algorítmica: 1) os comportamentos dos trabalhadores são avaliados e seus dados são rastreados; 2) as decisões também passam a ser automatizadas pelos algoritmos; 3 ) não há transparência nesta relação, pois os trabalhadores não tem acesso ao conjunto de regras e aos fundamentos da produção algorítmica; 4) os metadados são tratados e gerenciados por plataformas globais, porém impactam trabalhadores de diferentes localidades, submetidos a legislações locais; 5) o trabalho passa a ser gamificado, isto é, aplicam-se premissas e estratégias provenientes dos games no redesenho dos processos de trabalho; 6) busca-se intensificar sentimentos de independência, como se, pelo fato de não haver uma chefia direta, o sujeito estivesse em uma relação de plena autonomia, sem nenhum tipo de controle ou subordinação.

$\mathrm{Na}$ prática, a gestão algorítmica parece inclusive cercear os espaços de tomada de decisão e liberdades dos trabalhadores. Um motorista de Uber, por exemplo, deve aceitar suas viagens sem antes saber qual trajeto foi solicitado, assumindo o risco de fazer um trabalho que não será lucrativo. Igualmente, não há transparência quanto a política de cancelamentos (que inclusive pode culminar em exclusões arbitrárias da plataforma), de fixação das tarifas e preços dinâmicos determinados pelos algoritmos (Kalil, 2019). Se os trabalhadores não tem autonomia nem à participação quanto a delimitação dos valores dos serviços prestados, torna-se difícil crer na veracidade do discurso de liberdade prefigurado pela organização.

A gestão algorítmica da turkerização também produz assimetrias que incidem diretamente no cotidiano dos indivíduos. Restringem-se a comunicação entre os trabalhadores nas plataformas, hierarquizam-se os desempenhos e se criam insígnias e metas, cuja finalidade é a garantia do engajamento e de maior tempo de conexão dos sujeitos nas plataformas. Nessa mesma direção, amiúde são nebulosos os critérios de aprovação e rejeição das tarefas realizadas (Kalil, 2019), assim como os critérios de aceite e motivos de desligamento dos projetos (em especial na Appen). Embora possam manifestar suas demandas e inquietações via email ou intranet das empresas, os trabalhadores se deparam com formas limitadas, automatizadas e burocráticas de comunicação, o que faz com que seus poderes de negociação sejam irrisórios. 
A gestão algorítmica nas plataformas se serve da insegurança relacionada à quantidade de trabalho e da taskificação como vetores de manipulação à garantia do investimento libidinal (Gaulejac, 2011) dos trabalhadores. Todo tempo de lazer, de ócio e descanso, nessa perspectiva se torna passível de ser frutificado e rentabilizado, mediante a realização de tarefas. É ainda comum, no mercado de microtarefas, que os trabalhadores precisem assinar um contrato online, no momento do registro nas plataformas, denominado Non Disclosure Agreement ${ }^{7}$ (NDA). Costurados como aguda precisão jurídica, estes termos reafirmam que não se estabelece vínculo empregatício entre o trabalhador e a empresa, assim como definem obrigações de confidencialidade, as quais proíbem que sejam mencionadas, em quaisquer espaços externos à plataforma, informações sobre as tarefas que foram realizadas. Algumas plataformas do Grupo Pactera, como a Oneforma, por exemplo, chegam inclusive a exigir que o trabalhador faça um exame online, baseado neste acordo, colocando como condição de aprovação no mínimo 70\% de acertos nas questões objetivas apresentadas.

Em suma, quanto maior a dependência financeira do trabalhador a uma plataforma, maior será sua subsunção à gestão algorítmica e mais precárias serão suas condições de trabalho (Kalil, 2019). Precisamente na turkerização, a descentralização da força de trabalho, aliada à limitação das comunicações, ao receio do desligamento, às amarras jurídicas dos contratos e termos de confidencialidade, bem como ao ranqueamento dos desempenhos e à disputa por tarefas mais qualificadas, produz um cenário que favorece a desmobilização coletiva dos trabalhadores. Por conseguinte, o esvaziamento de sentido das atividades realizadas coloca entraves na construção identitária relacionada ao trabalho, doravante desprovido de significações sociais sólidas (Viana Braz, 2021).

\section{Considerações finais}

Quando problematizamos a turkerização segundo a óptica da produção de Saúde Mental no trabalho, nos deparamos com barreiras quase intransponíveis. Como dar sentido às atividades realizadas quando se está imerso em uma dinâmica de produção de tarefas repetitivas, de baixa complexidade, em que não há transparências quanto às suas aplicações e finalidades? Como criar estratégias para obtenção de prazer e satisfação no trabalho quando se revelam categóricas a insegurança e a descartabilidade?

\footnotetext{
${ }^{7}$ Acordo de Não Divulgação, em português.
} 
A fragmentação do trabalho no mercado de microtarefas esvazia componentes identitários elementares à realização profissional, bem como dispersa as possibilidades de projeções profissionais e de construção de memória coletiva no trabalho (Viana Braz, 2021). No plano social, é comum que estas formas precarizadas de trabalho sejam legitimadas pela teologia do empreendedorismo (Viana Braz, 2021), a qual associa o trabalho turkerizado à signos como autonomia, flexibilidade e liberdade. Celebram-se, contudo, virtudes de um sistema meritocrático abstrato e inexistente. Conforme discutimos neste artigo, ainda que não tenham uma chefia direta, estes trabalhadores são subordinados por gestões algorítmicas obscuras e arbitrárias, que os lançam em um círculo insidioso de precarização e desgaste mental. Sobretudo em casos de maior escassez material, ficam conectados o máximo de tempo possível, pois caso surjam novas tarefas, resta se debruçar sobre elas para fazer frutificar as oportunidades.

Se chamamos atenção para a turkerização, é porque vislumbramos trazer à tona dinâmicas de trabalho invisibilizadas, que parecem estar distantes dos debates públicos e nas mídias tradicionais. Não podemos correr o risco de cair no engodo de justificar estas relações de trabalho como se fossem alternativas viáveis e legítimas às pessoas que vivenciam situações de desemprego e decréscimo de poder aquisitivo. Ao corroborar este argumento falacioso, estaríamos sucumbindo ao que alguns economistas denominam nivelamento por baixo (Rodrik, 2011). Este é um ponto nevrálgico, pois o aumento da informalidade, atrelada à intensificação da taskificação e à plataformização do trabalho, tende a produzir um cenário em que a concorrência entre os trabalhadores se radicaliza, o direito à desconexão e à privacidade fica ameaçado e no qual se extingue definitivamente com as fronteiras entre tempo de trabalho e tempo de não-trabalho.

Por fim, finalizamos enfatizando que embora invisibilizados, estes trabalhadores são a espinha dorsal de uma cadeia produtiva tecnológica que se vende como ultra sofisticada e futurista, o suprassumo da automatização do mercado de serviços. Ao discutirmos a turkerização, compreendemos que na realidade a inteligência artificial se desenvolve a expensas de formas de trabalho substancialmente desregulamentadas, desprovidas de proteção social, trabalhalhista, nas quais humanos são ranqueados, reduzidos à números e à indicadores de desempenho. Estudos sobre o microtrabalho no Brasil, portanto, se revelam prementes, para que possamos apreender as particularidades vivenciadas por estes trabalhadores, de maneira a fomentar a criação de estratégias coletivas de mobilização, no sentido da luta pela garantia de condições seguras e produtoras de saúde no trabalho. 


\section{Referências}

Abilio. L.C. (2017). Uberização do trabalho: subsunção real da viração. Passa Palavra. 02 de fevereiro. Retirado de://passapalavra.info/2017/02/110685/

Abilio, L.C. (2019) Uberização: Do empreendedorismo para o autogerenciamento subordinado. Psicoperspectivas. Individuo y Sociedad. 18(3):1-11.

Abilio, L.C. (2020) Plataformas digitais e uberização: Globalização de um Sul administrado? Contracampo: Brazilian Journal of Communication. 39(1): 12-26.

Amazon Mechanical Turk. (2020) Overview of mechanical turk. Retirado de: https://docs.aws.amazon.com/AWSMechTurk/latest

Antunes, R. (2018) O privilégio da servidão: o novo proletariado de serviços na era digital. São Paulo: Boitempo.

Berg, J., Furrer, M., Harmon, E., Rani, U., \& Silberman M.S. (2018). Digital labour platforms and the future of work: Towards decent work in the online world, Geneva. International Labour Office.

Caldas, M. (2000). Demissão: causas, efeitos e alternativas para empresa e indivíduo. São Paulo: Atlas.

Casilli, A.A. (2019) En attendant les robots: Enquête sur le travail du clic. Paris: Seuil.

Gaulejac, V. (2007). Gestão como doença social: ideologia, poder gerencialista e fragmentação social. (I. Storniolo, trad.). Aparecida: Ideias \& Letras.

Gaulejac, V. (2011). Travail, les raisons de la colère. Paris: Éditions du Seuil.

Gray, M., \& Suri, S. (2019) Ghost Work: how to Stop Silicon Valley from Building a New Global Underclass. Boston: Houghton Mifflin Harcourt.

Grohmann, R. (2020) Plataformização do trabalho: entre dataficação, financeirização e racionalidade neoliberal. EPTIC, 22(1): 106-122.

Grohmann, R., \& Qiu, J. Contextualizando o Trabalho em Plataformas. Revista Contracampo, 39(1): 107-122. Retirado de: https://periodicos.uff.br/contracampo/article/download/42260/23968

Instituto Brasileiro de Geografia e Estatística (IBGE). (2020). Pesquisa Nacional por Amostra de Domicílios Contínua - Terceiro Trimestre de 2020. Retirado de: https://www.ibge.gov.br/explica/desemprego.php

Kalil, R.B. (2019) Capitalismo de plataforma e Direito do Trabalho: crowdwork e trabalho sob demanda por meio de aplicativos. Tese (Doutorado). Universidade de São Paulo, USP, Programa de Pós-Graduação em Direito, Direito do Trabalho e da Seguridade Social, 366f.

Kuek, S., Paradi-Guilford, C.M., Fayomi, T., Imaizumi, S. \& Ipeirotis P. (2015). The global opportunity in online outsourcing. Rapport, Washington, D.C., World Bank Group. Retirado 
de:

http://documents.worldbank.org/curated/pt/138371468000900555/The-globalopportunity-in-online-outsourcing

Manzano, M., \& Krein, A. (2020). A pandemia e o trabalho de motoristas e de entregadores por aplicativos no Brasil. Campinas: Cesit/Unicamp. Retirado de: https://www.cesit.net.br/wpcontent/uploads/2020/07/MANZANO-M-KREIN-A.-2020_A-pandemia-e-os-motoristas-eentregadores-por-aplicativo.pdf

Möhlmann, M., Zalmanson, L. (2017). Hand on the Wheel: navigating algorithmic management and Uber drivers' autonomy. Anais do International Conference on Information Systems (ICIS), COEX Convention Center, Seul. Retirado de : https://www.researchgate.net/profile/Mareike_Moehlmann2/publication/319965259_Hands on_the_wheel_Navigating_algorithmic_management_and_Uber_drivers'_autonomy/links/59 c3eaf845851590b13c8ec2/Hands-on-the-wheel-Navigating-algorithmic-management-andUber-drivers-autonomy.pdf

Moreschi, B., Pereira, G., \& Cozman, F.G. (2020). The brazilian workers in Amazon Mechanical Turk: Dreams and realities of ghost workers. Contracampo: Brazilian Journal of Communication, 39 (1): 44-64.

Nobles, S.U., \& Roberts, S.T. (2020) Elites tecnológicas, meritocracia e mitos pós raciais no Vale do Silício. Fronteiras - estudos midiáticos, 22(1):36-46.

Rizek, C. (2006). Viração e trabalho: algumas reflexões sobre dados de pesquisa. Estudos de Sociologia, 11(21): 49-58.

Rifkin, J. (2014). La nouvelle société du coût marginal zéro: L'internet des objets, l'émergence des communaux collaboratifs et l'éclipse $d u$ capitalisme. Paris: Editions Les Liens qui Libèrent.

Rodrik, D. (2011). A globalização foi longe demais? (M. Lopes, trad.). São Paulo: Editora Unesp.

Shumpeter, J. A. (1911). Teoria do desenvolvimento econômico. Coleção Os Economistas. São Paulo: Abril Cultural, 1982.

Van Doorn, N. (2017) Platform Labor: on the gendered and racialized exploitation of lowincome service work in the 'on-demand' economy. Information, Communication \& Society, 20(6): 898-914.

Viana Braz, M. (2019) Paradoxos do Trabalho: as faces da insegurança, da performance e da competição. Curitiba: Appris.

Viana Braz, M. (2021) Trabalho, sociologia clínica e ação: alternativas à individualização do sofrimento. Porto Alegre: Appris.

Woodcock, J., \& Graham, M. (2019) The gig economy: A critical introduction. Cambridge: Polity. 